\title{
CUADROS DE FUSILAMIENTOS, SS. XX-XXI. DE LA MÍMESIS AL FANTASMA
}

\author{
Mariano de Blas Ortega \\ Universidad Complutense, Madrid \\ mariabla@ucm.es
}

\section{RESUMEN}

Estudio de diversas obras visuales bajo la temática del fusilamiento y de la guerra como drama y agente embrutecedor que inicia Goya con su Tres de mayo de 1808. El hilo conductor es la mimesis de los elementos formales en diferentes argumentaciones y presentaciones artísticas ubicadas en los ss. Xx y xxi. Una aproximación mantiene una relación formal de hileras de verdugos y víctimas y otra arranca con el Guernica, que solo toma del Tres Mayo algunos elementos formales mientras que los verdugos son una referencia y las víctimas son bombardeadas y no fusiladas. Las dos aproximaciones se mantienen en los ejemplos paradigmáticos estudiados bajo diferentes artistas, medios y aproximaciones, para llegar desde la imitación al concepto de la copia como culminación de la mímesis. Finalmente el artista Ballester vacía de figuras los cuadros de referencia y aparecen los personajes solo en la memoria de la mirada como fantasmas.

Palabras clave: pintura, tema, concepto, intenciones, relaciones.

\section{PAINTINGS OF SHOOTINGS, XX-XXI C.} FROM MEMESIS TO GHOST

\section{Abstract}

This is a study of several visual works under the theme of shooting and war as a drama and as a brutalizing element that begins Goya with his Third of May 1808. The common thread is the mimesis of the formal elements in different arguments and artistic presentations located in the Xx and XxI centuries. One stream maintains a formal relationship of rows of executioners and victims and another starts with the Guernica who only takes from the Third of May some formal elements while the executioners are a reference and the victims are bombed and not shot. These two currents are maintained in the paradigmatic examples studied under different artists, means and approaches, going from imitation to the concept of copying as a culmination of mimesis. Finally, the artist Ballester empties the reference paintings of their figures that only reappear as ghosts in the memory of the look.

KEYwORDs. painting, subject, concept, purposes, relations. 


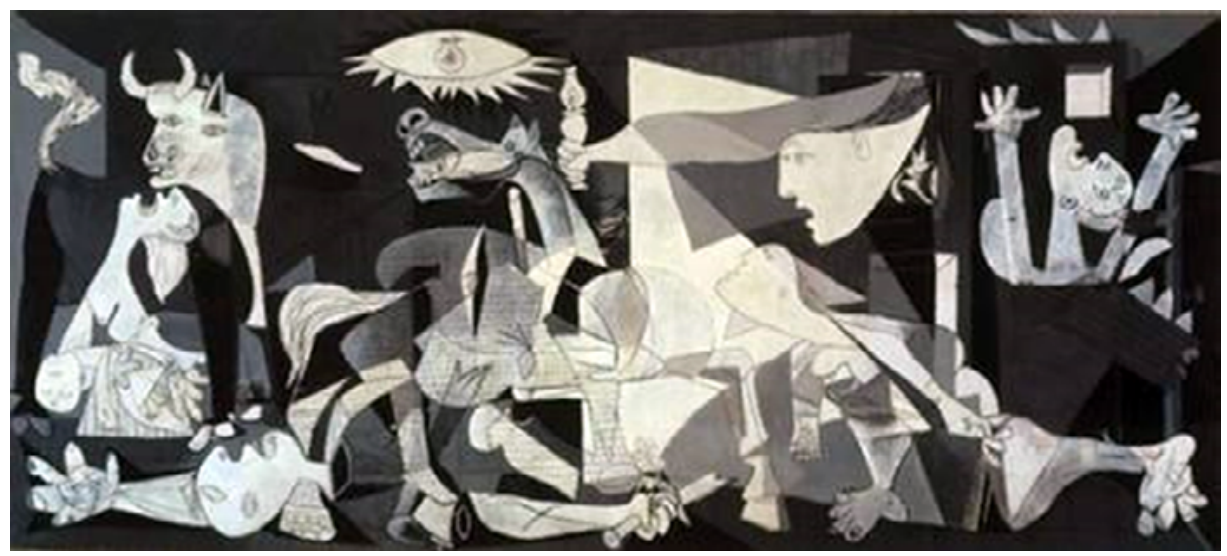

Fig. 1. Pablo Picasso. Guernica, 1937.

\section{INTRODUCCIÓN Y METODOLOGÍA}

Este estudio toma como hilo conductor la imagen del fusilamiento en obras pictóricas posteriores al cuadro del Tres de mayo de Goya (1814) (fig. 2), a saber, el Fusilamiento de Maximiliano de Manet (1867) (fig. 6) y, marginalmente, el Fusilamiento de Torrijos ${ }^{1}$ de Antonio Gisbert (1888) ${ }^{2}$ (fig. 7). Se presentan y analizan diferentes obras paradigmáticas que aportan nuevas aproximaciones conceptuales a lo largo del siglo xx y hasta el presente, como son la apropiación, la originalidad, el simulacro, el mimetismo, la pertinencia de su contenido y, finalmente, la desaparición y su evocación.

Se establecen dos ejes principales, el primero se sustenta en el Tres de mayo (fig. 2) y se deriva en dos obras de Picasso, el Guernica (fig. 1) y Masacre en Corea (fig. 3), seguidas de otras iconológicamente relacionadas, hasta concluir en la realizada por Ballester. El segundo se apoya en el Fusilamiento de Maximiliano (fig. 6) y se deriva a las versiones realizadas por el Equipo Crónica, Minjuim y Di Matteo.

Goya se refiere a los civiles como víctimas de seres deshumanizados representados por soldados entendidos como una masa anónima. Manet incide más en los aspectos conceptuales y formales de la pintura. Con él, la narración del suceso está al servicio de un acontecimiento visual, en el que el cuadro es un todo, en donde conviven personajes, acción, luz, colores y formas. «La sensación no es un dato, sino

1 Título completo: Fusilamiento de Torrijos y sus compañeros en las playas de Málaga.

2 Publicado por este autor como «Los cuadros de fusilamientos en el siglo xix. Una discusión de intenciones». Bellas Artes: revista de artes plásticas, estética, diseño e imagen n. 11 (La Laguna: Universidad de La Laguna, 2013): 55-80. 


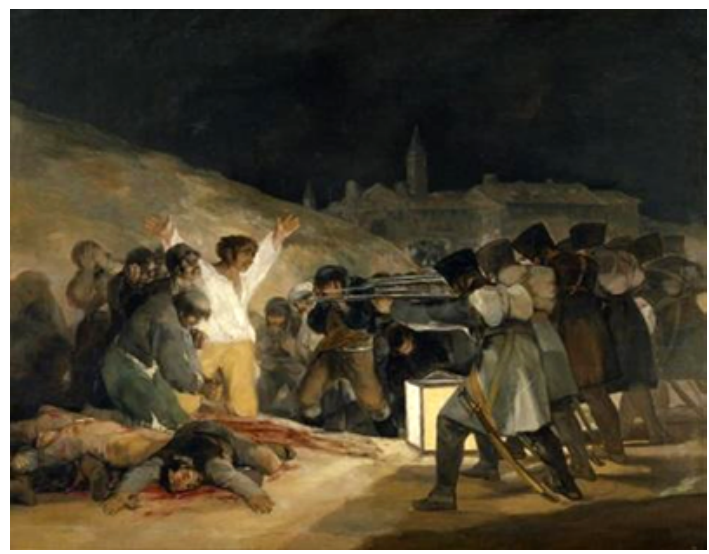

Fig. 2. Francisco de Goya. Tres de mayo de 1808, 1814.

un estado de la conciencia» ${ }^{3}$. El Fusilamiento de Torrijos (fig. 7) encabezaría otro eje centrado en la represión ideológica que se manifiesta en las ilustraciones, además de que su pertinencia plástica académica ha ido perdiendo interés en los siglos posteriores, sin que por ello no sea una gran obra de arte, pero hay que tenerla en cuenta porque se interrelaciona con obras de los dos ejes principales. Partiendo del tema de la ejecución realizado por Goya, Manet y Picasso, este estudio analiza las derivas conceptuales y de contenido formal hasta concluir en el presente. Se comparan la composición, intenciones y otros elementos de diversas obras, estableciendo un sistema de relaciones.

\section{GUERNICA Y MASACRE EN COREA}

Cuando Picasso pinta el Guernica en 1937, el mundo del arte y desde luego él mismo esperan que se realice una obra a la altura de Velázquez y Goya, los dos grandes referentes de la pintura española, con sus dos obras referenciales sobre el tema épico de la guerra, la Rendición de Breda y el Tres de mayo. Evidentemente quería evitar el anacronismo de recrear la historia con la pintura en la Modernidad. Así lo hace Picasso, pero coincide con Goya en mantener un fuerte contenido emocional y crítico con la guerra, manteniendo su distancia con la narración literaria de la historia y de los valores heroicos ideológicos ${ }^{4}$.

${ }^{3}$ Gulio Carlo Argam, El arte moderno 1 (Valencia: Fernando Torres, 1975): 112-115.

${ }^{4}$ Gertje Utley, «From Guernica to The Charnel House: The Political Radicalization of the Artist», en Steven A. Nash and Robert Rosenblum, eds., Picasso and the War Years 1937-1945 (New York: Thames and Hudson Inc., 1998). 


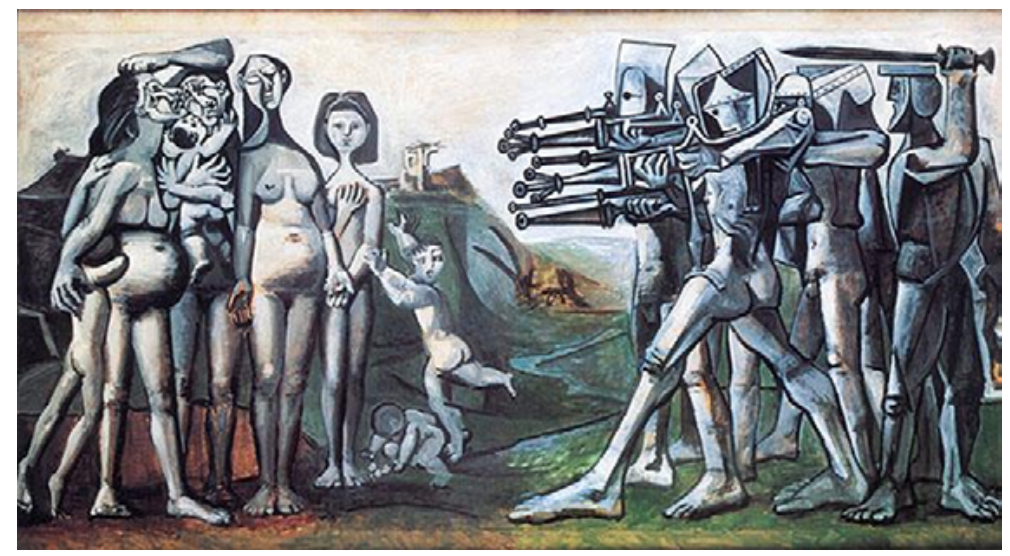

Fig. 3. Pablo Picasso. Masacre en Corea, 18 de enero de 1951.

El Guernica presenta diversas referencias con el Tres de mayo. En ambas, los personajes son anónimos, con un gran contenido simbólico genérico. No hay nombres propios y todos nos podemos sentir identificados con ellos. Velázquez también retrata en la Rendición de Breda a muchos soldados anónimos, pero bajo las dos figuras señeras de los dos generales, Spínola y Nassau. Cualquiera se puede sentir vinculado con los ejecutados de Goya, todos hermanados anónimamente frente a la muerte. Picasso no solo presenta a esos mismos personajes masculinos del común, sino que las referencias se extienden, hay mujeres, un bebé y su madre, estatuas rotas esparcidas y dos animales emblemáticos. Uno casi universal, el caballo, está herido. Otro, más particularmente español, el toro, que no es verdugo porque está participando de la tragedia de la escena causada por algo ajeno a lo que se presenta ${ }^{5}$. Los verdugos en el Guernica son los pilotos desde la distancia emocional de sus aviones, mientras que los soldados de Goya están cercanos a sus víctimas y los ven morir, con el impacto emocional para el verdugo que ello supone $e^{6}$. La guerra moderna permite matar, a veces, desde una confortable distancia emocional porque no se percibe la muerte y el sufrimiento de las víctimas. Con el título del Guernica, Picasso no solo señala un suceso, sino que además se posiciona, denuncia una atrocidad paradigmática por el bando fascista y sus sostenedores, los aviones nazis de la Legión Cóndor, aunque se constituya también en una denuncia genérica de la violencia.

5 Rudolf Arnheim, El Guernica de Picasso. Génesis de una Pintura (Barcelona: Gustavo Gili ed., 1976). Gijs van Hensbergen, Guernica. The biography of a twentieth-Century Icon (New York: Bloomsbury, 2006). Pierre Cabanne, El siglo de Picasso III (1937-55). La Guerra (Madrid: Ministerio de Cultura, 1982).

${ }^{6}$ A veces se reparten aleatoriamente cartuchos sin bala para que no se sepa si el disparo ha matado o no. 


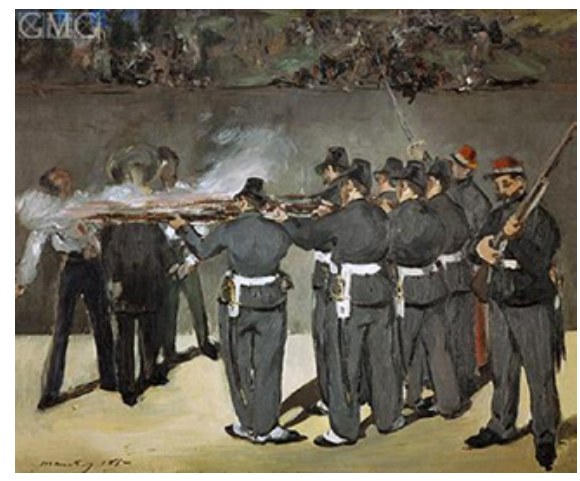

Fig. 4. Édouard Manet. Ejecución de Maximiliano de Méjico. Segunda versión, 1867.

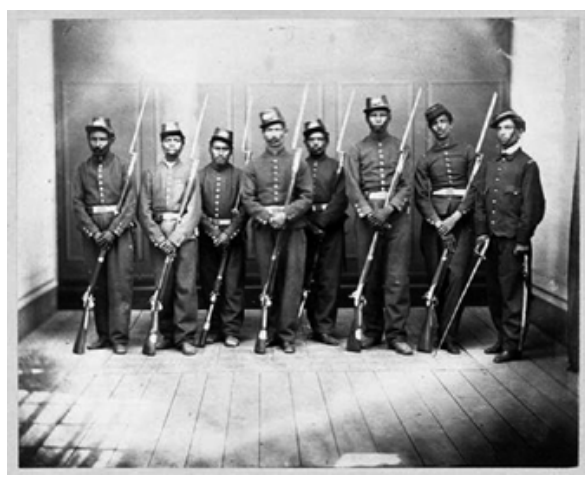

Fig. 5. Francois Aubert. Pelotón de fusilamiento de Maximiliano 1867. Fotografía.

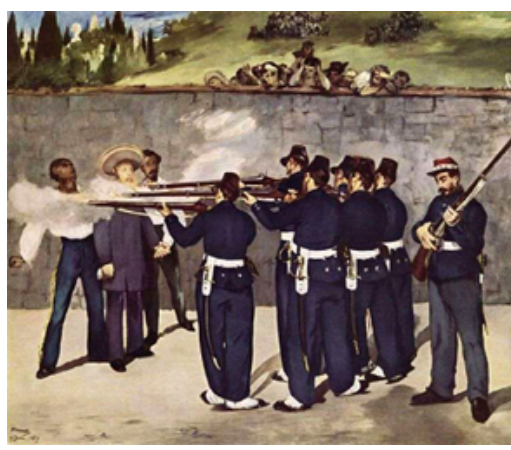

Fig. 6. É. Manet. Ejecución de Maximiliano de Méjico. Cuarta versión, fechada el día del fusilamiento 19-06-1867 (pero que se supone comenzada en septiembre).

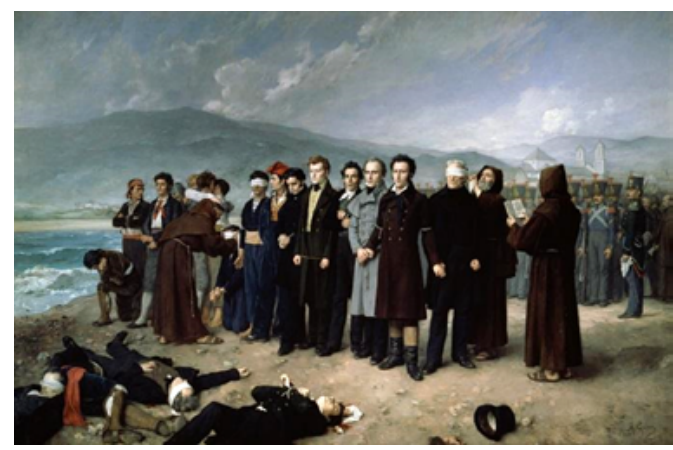

Fig. 7. Antonio Gisbert Pérez. Fusilamiento de Torrijos y sus compañeros en las playas de Málaga, 1888.

Goya pinta dos grandes focos de luz, la del farol y la que ilumina la camisa blanca del personaje con los brazos en alto, que a su vez se convierte en un segundo foco de luz. Picasso también presenta dos focos de luz, la bombilla y el candil de la figura que emerge desde detrás de la casa en llamas. La luz de la denuncia frente al horror de la sinrazón y la estupidez trágica de la guerra, el fracaso de la inteligencia, esos son los enemigos, no los soldados de un determinado ejército, nacional, al servicio de una corona o bajo las siglas de un partido. En ambas obras, estas luces iluminan la escena del crimen, actúan como un recurso narrativo y testimonial de lo que allí está ocurriendo. No es tanto un acontecimiento visual sino uno expositivo. Es la imagen puesta a disposición del mensaje de una idea, más allá de la plástica, a pesar de emplearse medios excepcionales y excelentemente pictóricos. 
Los personales de los brazos en alto están presentes en ambas obras, aunque el del Guernica tiene menos protagonismo que el del Tres de mayo. El espacio en ambas obras está muy cerca del espectador que se representa en la escueta parte inferior de las obras. Así el espectador no está contemplando el suceso desde una distancia, sino que está dentro de la escena, involucrándole. Se le seńala que es parte de las víctimas de Guernica, está siendo bombardeado como los demás. Con Goya hay dos opciones, puede ser uno de los soldados, incluso el oficial que manda el pelotón de fusilamiento, que no aparece en el cuadro pero que ha de estar presente impartiendo las órdenes pertinentes, como se puede apreciar en las figs. 3 y 4, o, al contrario, uno de los condenados que está esperando su turno fatal.

En 1951 Picasso estaba posicionado con la izquierda y el Partido Comunista Francés (PCF), que le pidió un cuadro alusivo a la guerra de Corea. Es entonces cuando pinta Masacre en Corea. Fue interpretado como una crítica al bando occidental; sin embargo, no fue del agrado del PCF, más interesado en «los panfletos visuales del Realismo Socialista», en donde el proletariado no debía aparecer como una víctima sino como un héroe, coincidiendo con los cuadros de historia del clasicismo, en donde los héroes, generales y valientes soldados, son los protagonistas. Con el realismo socialista, estos se transforman en líderes del partido y del pueblo, al que guían y al que se le exige que sea heroico para la causa comunista.

Picasso no era apreciado como artista por el PCF, controlado entonces por Stalin. Era soportado por su fama internacional y por el prestigio que aportaba. Las preferencias del PCF iban por jóvenes artistas seguidores del realismo socialista como André Fougeron y Boris Taslitzky, ambos militantes y antiguos miembros de la resistencia. Volviendo a Masacre, se ha propuesto ${ }^{8}$ una relación con la Matanza de Sinchon de 1950 en Corea del Norte, en donde fueron fusilados simpatizantes comunistas, incluyendo mujeres y niños. Sin embargo, Picasso no la relaciona explícitamente, ni con el título ni con la obra; además, las matanzas se cometieron en ambos bandos. No hay referencias concretas en los personajes, tampoco en dónde o por quién es la masacre. El título es muy general, Masacre en Corea, más bien parece una alusión a una guerra (una más) y además también civil, lo que para un español como era él, es significativo. Esto invalida la idea de que la obra sea un alegato procomunista, ya que desde esa perspectiva y en aquella época, su mensaje político no era claro y ortodoxo. Como el Guernica, se trata de una masacre universal y genérica, no el discurso heroico de un bando ideológico determinado.

El paisaje del cuadro presenta un río que evoca la frontera entre las dos Coreas. Las líneas curvas de los civiles contrastan con las rectas y quebradas de los soldados con sus cascos, que los vinculan con robots y máquinas. Los civiles presentan un mosaico de expresiones de estupor, dolor y miedo, en eso se relaciona con

\footnotetext{
Press, 2000).

${ }^{8}$ Cabanne, op.cit. Y Roland Penrose, Picasso. His life and work (New York: Harper\&Row, 1973) (1. ${ }^{a}$ edición 1958).
}

7 Gertje Utley, Picasso: the Communist Years (London \& New Haven, Yale University 
las de Goya. Picasso es un maestro del retrato expresionista sustentado en la línea, en donde el color presenta un valor dramático por su ausencia, como en el Guernica. Los personajes son anodinos pero también representan una tipología general de personas convertidas en víctimas y de verdugos embrutecidos. Establece dos planos simultáneos como Goya, en donde los civiles están personalizados, al contrario que los soldados. En estos también está la figura del jefe, como en Manet ${ }^{9}$, una suerte de oficial blandiendo una espada para comandar la orden de disparar. Un pelotón de fusilamiento tiene que estar al mando de un oficial, como así se atestigua en las figs. 5 y 7. Este oficial aparece en la segunda versión (fig. 4), un boceto de $50 \times 61 \mathrm{~cm}$, que después eliminaría en la cuarta y definitiva, una obra terminada de $225 \times 305 \mathrm{~cm}$.

En Masacre, el tiempo está detenido como en el Tres de mayo, solo es ligeramente alterado por el niño de la derecha corriendo. Mantiene la composición típica de una ejecución, como así se muestra en las ilustraciones y fotografías contemporáneas, una fila de verdugos y otra de víctimas, que Goya lleva novedosamente a la gran pintura de los cuadros de historia. Con Masacre está reforzado su dramatismo por la desnudez de todos los personajes, en donde el único asexuado es el comandante del pelotón. Sin duda la omisión de los genitales masculinos, tan importante para un artista tan machista como Picasso, tiene una intención formal interesada. La escena no deja dudas en apelar a los sentimientos y a la indignación de la cobardía de unos grotescos soldados, de cascos y de armas, a punto de disparar a mujeres, una embarazada, y a sus hijos. Con Picasso, la desnudez de tres madres y una adolescente está relacionada con la dignidad de la belleza clásica, de su referencia en el cuerpo. No son humilladas por estar desnudas, sino que es la mirada turbia del que lo pretende la que es sujeto de desprecio. Se representa al cuerpo como paradigma del clasicismo, como una alusión de la belleza bajo el lenguaje de la mitología. No se refiere a la desnudez del mártir, ni a la cristiana carne exhibida como sujeto de tentación y pecado.

La paleta es grisácea, como en el Guernica, pero con acentos de amarillo $\mathrm{y}$ verde. Es un cuadro expresionista con algunas fórmulas cubistas de simultaneidad de los planos, logrando fuerza visual y dramatismo. El pie del primer soldado invade el espacio agresivamente, lo que contrasta con el gesto de Venus Púbica ${ }^{10}$ de la adolescente y los gestos receptivos de la madre del centro. Significativamente los Desastres de la Guerra de Goya habían formado parte de una exposición solo varios meses atrás de aquel enero del 51 y reproducidos un mes antes en L'Humanité.

9 Wikipedia. Category:Execution of Emperor Maximilian I of Mexico by Manet https:// commons.wikimedia.org/wiki/Category:Execution_of_Emperor_Maximilian_I_of_Mexico_by_ Manet y National Gallery, the. The execution of Maximilian. https://www.nationalgallery.org.uk/ paintings/edouard-manet-the-execution-of-maximilian (consultados 28-8-20).

${ }^{10}$ En la mitología romana Pudicitia (Aidòs en la griega) era la personificación de la modestia y la castidad. Rebecca Langlands, Sexual Morality in Ancient Rome (Cambridge: Cambridge University Press, 2006): 25. 


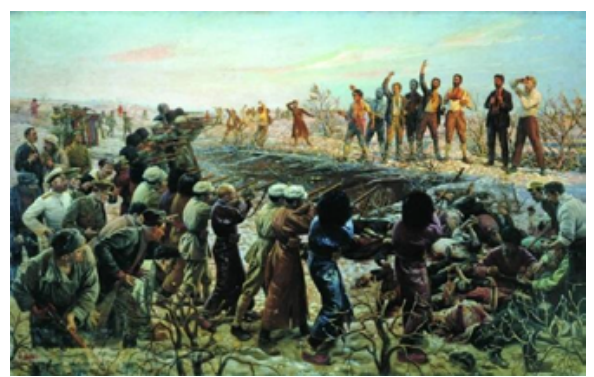

Fig. 8. Isaak Brodsky. Ejecución de los veintiséis comisarios de Bakú, 1925.

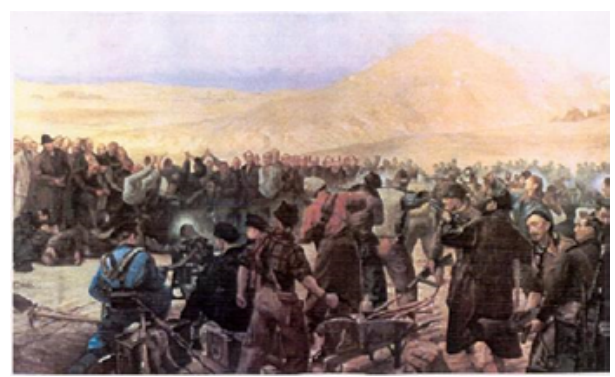

Fig. 9. Carlos Sáenz de Tejada. Españoles, perdonad pero no olvidéis, c. 1948.

Ejecución de los veintiséis comisarios de Bakú (fig. 8) y Españoles, perdonad pero no olvidéis (fig. 9) continúan la saga temática. Es paradójico que ambas obras denuncien unas ejecuciones, comisionadas por dos regímenes, soviets y franquistas, tan proclives ellos mismos a fusilar a sus opositores, incluyendo civiles.

Estas dos obras se parecen entre sí, estilísticamente y en su contenido heroico. Ambas serían del gusto del realismo socialista estalinista o del nacionalcatolicismo franquista. Son de grandes dimensiones. La de Isaac Brodsky (fig. 8) mide $285 \times 176.5 \mathrm{~cm}$ sita en el Museo de Volvogrado (ex-Stalingrado). La de Carlos Sáenz de Tejada (fig. 9) tiene $320 \times 200 \mathrm{~cm}$, está en el Museo del Ejército de Toledo. Los ejecutores y las víctimas son de ideas políticas antagónicas. Aluden a poses heroicas con tratamiento narrativo y de ilustración. Carecen de la potencia narrativa y compositiva de Fusilamiento de Torrijos. Las composiciones son abigarradas y confusas. Constituyen un ejemplo de adocenado lenguaje academicista, al contrario que Gisbert, que es capaz de construir una gran obra expresiva con el neoclasicismo académico.

Los ejecutores en primer término están en su mayoría de espaldas, pero las víctimas, que están de frente y por ello pudiendo aportar mayor expresividad sus rostros, quedan anuladas por la distancia. De esta manera se enfatiza a los ejecutores, no a las víctimas. Interesa denunciar la maldad del enemigo, acaso para justificar su eliminación en la realidad. Los autores identifican claramente a los 'malos', con gorros y uniformes: oficial zarista, gorros caucásicos; guardias de asalto, milicianos a la rusa y anarquistas. Sáenz se refiere a la ejecución de presos por la República en Paracuellos del Jarama, Madrid, entre noviembre y diciembre de 1936. Los 26 comisarios pertenecían a la Comuna de corta vida de Bakú (Azerbaiyán) cercanos a Lenin, en 1925 y fueron ejecutados por fuerzas de los rusos blancos. Las dos obras también se refieren a una guerra civil.

En estas dos obras a colación, el gusto fascista del primer franquismo coincide significativamente en el concepto pictórico del realismo socialista soviético, situado en este caso en el corto periodo que media entre la muerte de Lenin y la toma de las riendas del poder por Stalin. Tan solo varía la narración de la historia. En Paracuellos, los ejecutores son izquierdistas y las víctimas derechistas detenidos 


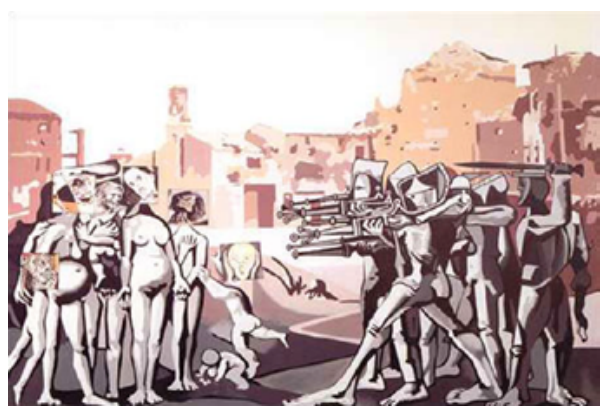

Fig. 10. Equipo Crónica. Los monstruos, 1974.

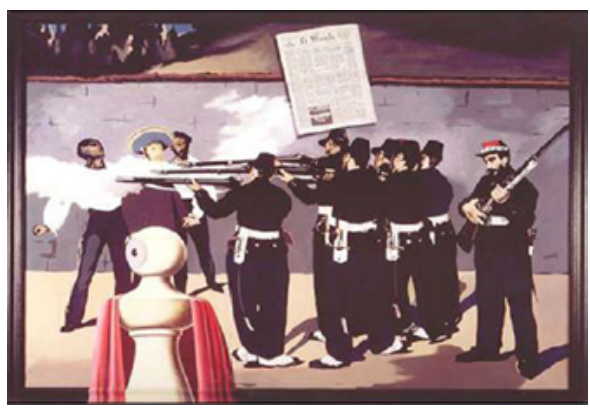

Fig. 11. Testigo ocular, 1974.

bajo la protección de la República. De izquierda a derecha: los guardias de asalto disparan la ametralladora hasta llegar a un miliciano con gorro ruso y camisa roja que se refiere a un comunista. Los anarquistas intervienen en la escena como auxiliares. Se les reconoce por el gorro de uno y el pañuelo del otro, ambos rojinegro. Están casi fuera de cuadro, a la derecha del borde inferior, muy alejados del centro.

En estas dos obras la composición es abigarrada y confusa, en dos masas, la delantera atropella a la de los fusilados. Este contenido se relaciona con la temática del Fusilamiento de Torrijos y también es una ejecución por razones ideológicas en un conflicto de guerra civil. En estas obras es esencial la narración concreta con un motivo aleccionador y referencial.

\section{EQUIPO CRÓNICA Y MORIMURA}

Antes de abordar otras obras más recientes, es interesante mostrar cuatro trabajos del extraordinario Equipo Crónica (Manuel Valdés y Rafael Solbes), inscritas en el realismo crítico pop. Las dos primeras, Los monstruos (fig. 10) y Testigo ocular (fig. 11), hacen referencia a los fusilamientos de Picasso y Manet. Presentan una inteligente ironía, con un trasfondo de denuncia al desasosiego de la dictadura de Franco. De manera estratigráfica presenta anacronismos y referencias a pastiches y a otras obras de arte. En Los monstruos, el rostro de El grito de Munch. En Testigo ocular, la pieza del rey y una nota de prensa desdoblan la visión en las reproducciones de las obras de referencia, actualizando su referente simbólico.

El paredón (fig. 12) se refiere a los últimos fusilamientos del franquismo el 27-9-75, resultando que las dos primeras citadas fueron premonitorias. El paredón sigue la línea temática de este estudio de obras sobre fusilamientos pero con un planteamiento formal completamente distinto. Solo aparece una figura que recoge una cabeza de Francis Bacon, con los ojos tapados aludiendo al anonimato del rostro, que puede ser el de todos. Frente a esta barbarie, el arte se rompe en los pedazos de la paleta de pintor, que Goya y Velázquez exhiben en alguna de sus obras. El fondo lo constituye un explícito paredón de ladrillos que atisban un paisaje posterior. 


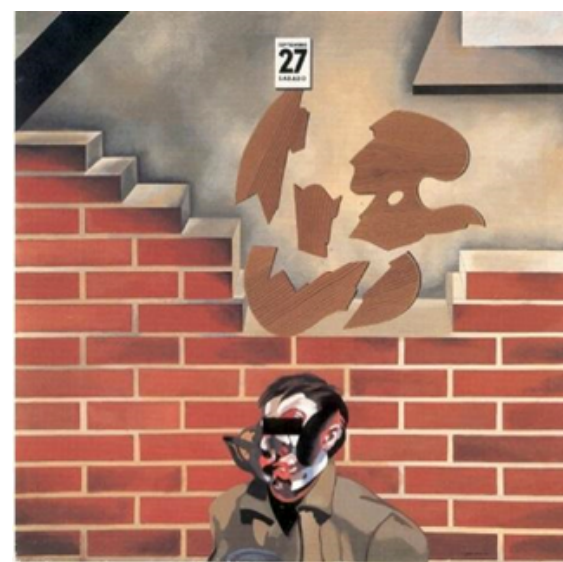

Fig. 12. Equipo Crónica. El paredón, 1976.

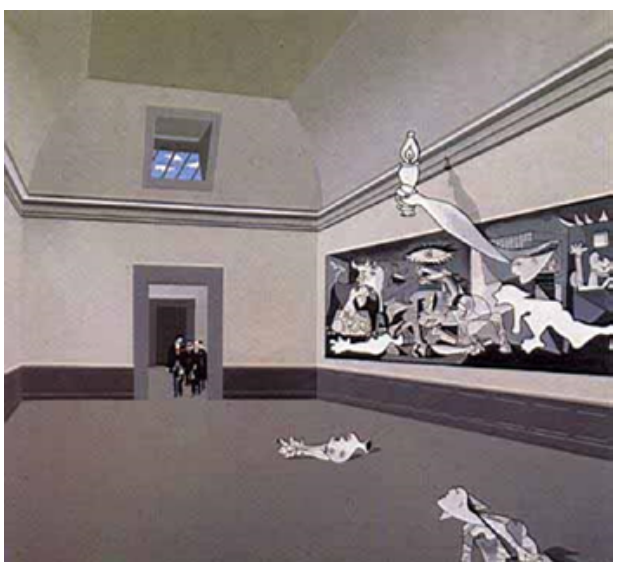

Fig. 13. La visita, 1969.

Con La visita (fig. 13), el Guernica parece estar ubicado en su asentamiento actual, el Museo Reina Sofía de Madrid, un antiguo hospital. Pero en 1969 estaba en el MOMA, por lo que la imagen es premonitora. La severa sala de La visita tiene un ventanal abierto a un cielo azulado quizás en alusión a la esperanza. Entonces el Guernica tenía un significado de contestación por el franquismo imperante ${ }^{11}$. Los visitantes emergen de una puerta que recuerda a la de Las meninas, incluso al espejo con los reyes. Los dos fragmentos del Guernica en el suelo, han pasado a esta realidad presente de la virtualidad del cuadro, iluminados por la mano que porta la antorcha de la ¿̨libertad?, actuando de conexión entre dos mundos, el del arte y el real, cuando todo está dentro la obra misma que engloba. Es similar al recurso del trampantojo en el cuadro que se sale del marco que había pintado Murillo con su mano en su Autorretrato de 1670.

La ironía del Equipo Crónica se convierte en caricatura con las versiones de Goya de Morimura (fig. 14), que alcanza el esperpento en la segunda versión (fig. 15), en donde aparece un torero (arquetipo español) como cadáver. El icono del Tres de mayo pasa a versiones más populares, como grafiti (fig. 16) y como carátula del disco (fig. 17) Ni un paso atrás del grupo sevillano de rock Reincidentes, que se publicó en 1991. Un año antes de la conmemoración del Descubrimiento de América. En este ejemplo los indígenas son ejecutados por soldados vestidos a la usanza española del s. XVI, con sus característicos morriones.

En la fig. 18, un pelotón de mujeres fusila a unos barbudos, ironía con las sombras. De autor desconocido, fue expuesto en el Centro Dos de Mayo de Mósto-

${ }^{11}$ Cuando se trajo a Madrid en 1981 en su primera ubicación del Casón del Buen Retiro tenía un cristal protector antibalas por la oposición que despertaba en los sectores de ultraderecha. 


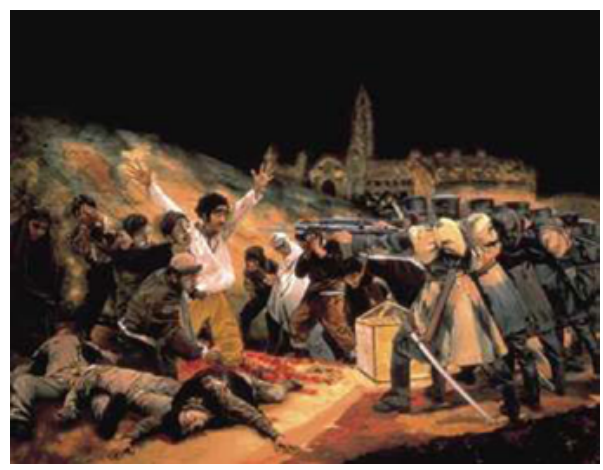

Fig. 14. Yasumara Morimura.

Hermanos. Masacre 1.

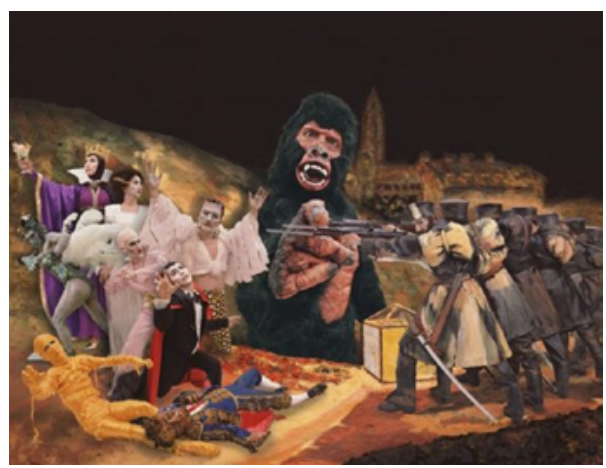

Fig. 15. Masacre 2, 1991.

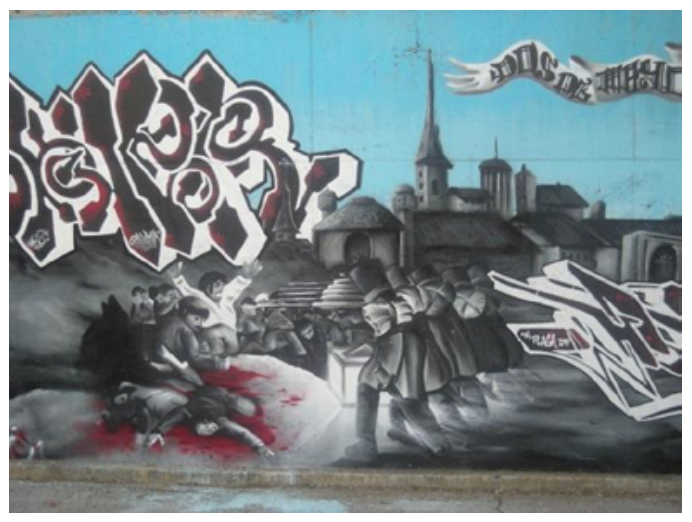

Fig. 16. Grafiti en Madrid.

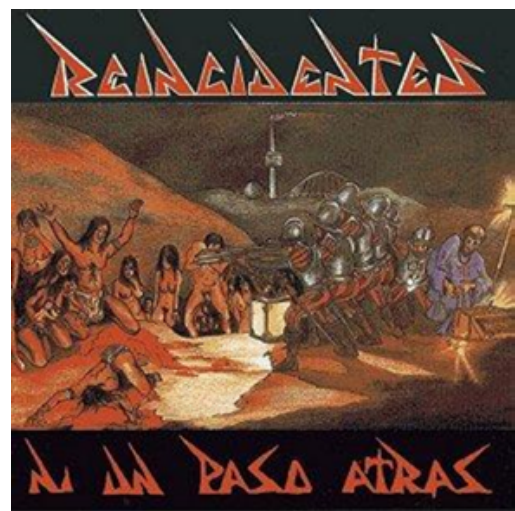

Fig. 17. Reincidentes.

Ni un paso atrás, 1991.

les (Madrid) en 2008. Finalmente se llega al mundo del juego con figuritas de Playmobil (fig. 19). Los soldados están definidos con el chacó estilo inglés que llevaban los españoles y portugueses desde c. 1810 con uniforme azul. Hay una alusión a la Guerra de las galaxias (fig. 20), con su épica maniquea y elementos mágicos, tales como La fuerza y los rebeldes (fusilados) y El lado oscuro (verdugos), que se enmarca en un mundo de ciencia ficción. Estos son diversos ejemplos de hiperrealidad en donde el modelo y el drama del original han desaparecido siendo sustituidos por un nivel más banal o cómico. Compárese con una tragedia real, mediante la fotografía de Centelles (fig. 21); aquí los niños juegan a lo que perciben del ambiente, en este caso los viles fusilamientos arbitrarios de los piquetes de milicianos, pero la escena podría ser del bando nacional con las atrocidades de los militares y milicias rebeldes (fig. 22). 


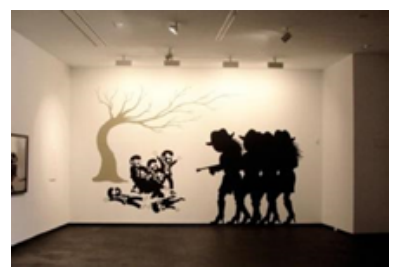

Fig. 18. Anónimo, 2008.

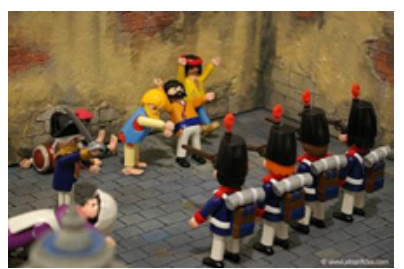

Fig. 19. figuritas de Playmobil.

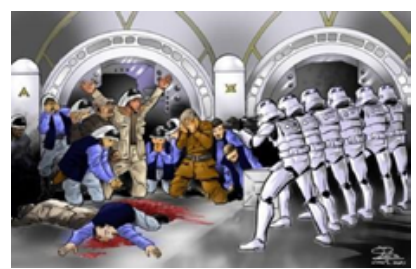

Fig. 20. Sin datos.

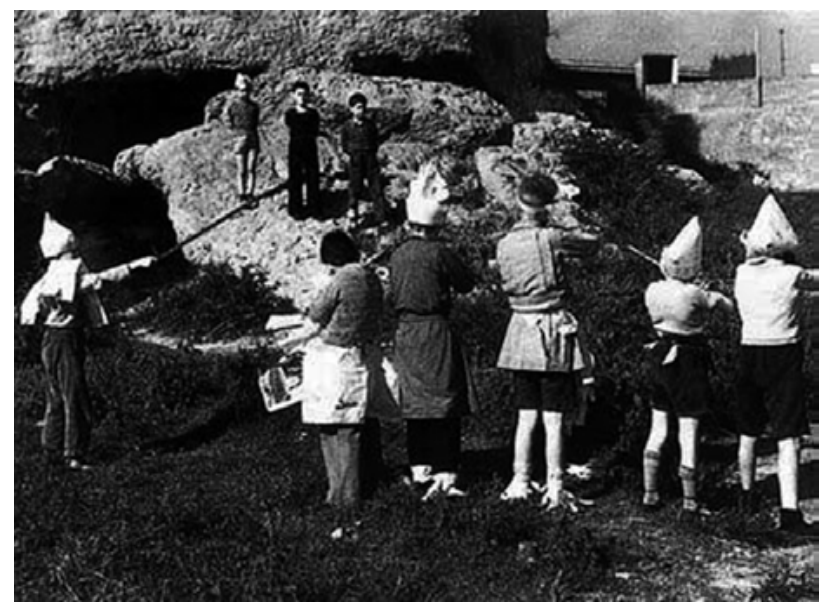

Fig. 21. Agustí Centelles. Niños jugando a los fusilamientos. Barcelona, 1937.

Centelles trasciende del documento para mostrar un drama complejo con una ingeniosa retórica; de la misma manera que Goya tratara el tema de la guerra y el embrutecimiento en el anonimato, los niños del pelotón de fusilamiento también van cubiertos con gorros como los soldados de los cuadros tratados y como en la fotografía de la fig. 22. Con el 'fusilamiento' de una estatua/monumento (fig. 23) se atenta contra la simbología de un contrario, no hay nada nuevo en la larga historia de sustituciones ideológicas (incluyendo las religiosas), lo interesante es la representación de su procedimiento. El monumento fue dinamitado y 'fusilado', lo que constituye solo un ritual. Se podría señalar, desde la perspectiva del presente, que los milicianos (bajo la mirada de la miliciana ¿oficial al mando?) realizan una performance. Con esta fotografía, los cuadros de fusilamientos se pueden abordar como un paradigma artístico, y por ello simbólico, que trasciende a la mera pintura. Se muestran como una manera de eliminación de un opuesto y ese proceder solo resulta de la brutalización de sus autores, de su anulación como individuos pensantes. Esa es la argumentación de la representación simbólica del lúcido Goya. 


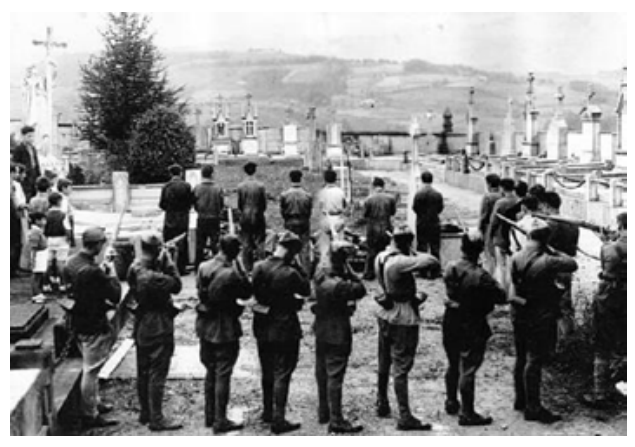

Fig. 22. Zaragoza, 1937.

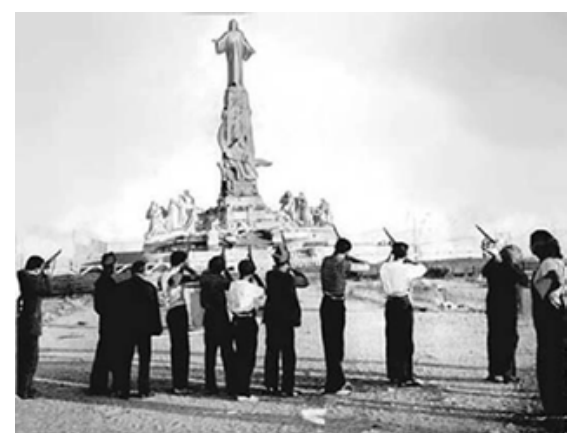

Fig. 23. Fusilamiento al Sagrado Corazón de Jesús en el Cerro de los Ángeles en Madrid el 28 de julio de 1936.

\section{YUE MINJUN, EJECUCIÓN}

Esta obra (fig. 24) hace obviamente una referencia a los fusilamientos de Manet y más indirectamente al de Goya. Constituye un realismo neopop contemporáneo que no pretende documentar nada, en donde las influencias de la fotografía, incluyendo la publicidad, el cine, el cómic y los videojuegos, son evidentes ${ }^{12}$. El personaje de la derecha rompe con la fila del pelotón, como en la obra de Manet. Minjun explica que esa figura tiene las manos a la misma altura que la de Manet. También la valla roja se relaciona con el espacio cerrado del fusilamiento de Maximiliano. Se podría suponer que esta valla es la de Tiananmen, afuera de la Ciudad Prohibida. Se han suprimido las personas que aparecen en Manet detrás del muro. La fila de fusilados están en slips (calzoncillos ajustados) en una cultura más mojigata (y represiva) que la occidental, con relación al cuerpo, lo que la hace más extraña al puritanismo chino al uso ${ }^{13}$.

Minjun realiza, como es en él habitual, una deconstrucción del arte occidental. Todos sus personajes son autorretratos riéndose con la boca abierta, lo que es muy significativo en una cultura como la china, en donde el individuo se pliega a lo colectivo, además de que la expresión de las emociones se inhibe. Podría ser así un absurdo a sus premisas culturales. Se ha relacionado también con el tradicional Buda Sonriente, o una "pseudo irónica respuesta al vacío espiritual y la locura de la

12 Wikipedia. Execution (painting) http://en.wikipedia.org/wiki/Execution_(painting) (consultada 29-8-20).

${ }^{13}$ Li Xianting, «The Cynical Realist Works of Yue Min Jun and Yang Shao Bin», en Faces Behind the Bamboo Curtain (Hong Kong, Schoeni Art Gallery, 1994). 


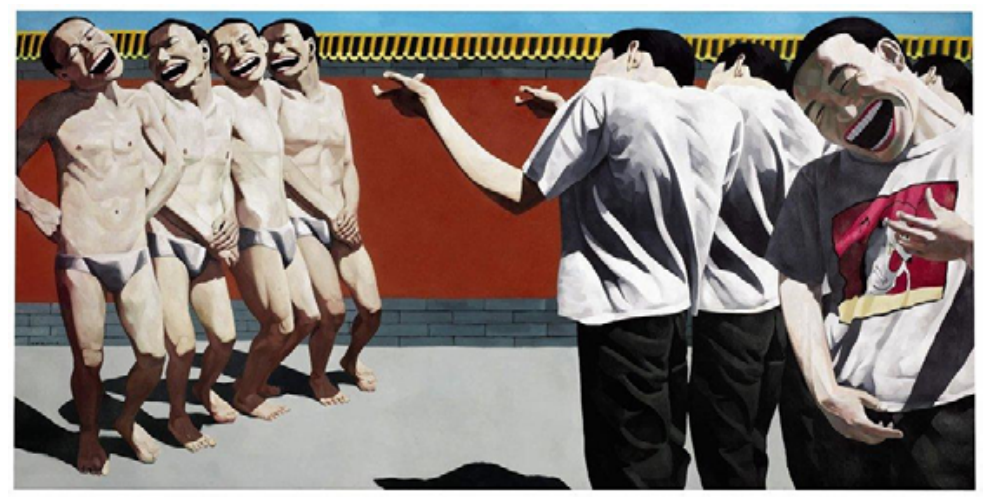

Fig. 24. Yue Minjun, Ejecución, 1995.

China moderna» (Li Xianting) ${ }^{14}$. Es significativo que un artista chino cuya tradición cultural inhibe el personalismo individualista, al relacionarse con la cultura occidental capitalista hipertrofia su propia imagen. Su obra es una alusión a su ego, él es el único protagonista mediante una repetición, incluso dentro de la obra, de su propia imagen, en una imagen de risa ubicua. También se puede relacionar con la imagen tradicional del Buda que ríe, tan diferente de la cristiana (los santos nunca se ríen).

Este artista dice que en la época del realismo socialista, cuando China no se había introducido en el mundo capitalista, la propaganda mostraba a sus épicos personajes a menudo sonriendo, cuando lo que imperaba era una seriedad social que albergaba la tristeza imperante bajo la represión maoísta. Era una representación del paraíso socialista en donde todos oficialmente estaban felices y sonrientes. Se imponía una representación opuesta a la realidad.

Minjun compara explícitamente su obra con el Tres de mayo, en cuanto que hace notar que sus fusilados tienen los brazos caídos porque no temen a la muerte. Él no se plantea que los brazos alzados se hayan interpretado en la iconografía espańola y occidental como un desafío, el toro que muere embistiendo, atacando. Aunque también se ha argumentado que se corresponde a un crucificado, habida cuenta de que este personaje de Goya muestra estigmas en las manos ${ }^{15}$.

Todos los personajes en el cuadro aparentan algo que no es. La fila del supuesto pelotón de fusilamiento parece que va vestida de soldado uniformado y hace como que sostiene un arma. Los supuestos ejecutados, en hilada, se parten de

${ }_{14}$ Li Xianting, Yue Minjun Exhibited at The Saatchi Gallery, 2005. http://www.saatchigallery.co.uk/artists/yue_minjun.htm (consultada 29-8-20).

${ }^{15}$ Elizabeth Yuan, Painting's owner 'un-Executed', 2007. http://edition.cnn.com/2007/ WORLD/asiapcf/10/12/china.artist/index.html (consultado 18-7-17). 
risa mientras que fingen que se van a enfrentar a la muerte. Aparentan ser varias personas cuando es solo el rostro del autor. Yue tiene razón en no reconocerse en la denominación de realista crítico, acuñada por el crítico Li Xianting ${ }^{16}$, para referirse a la generación de artistas desilusionados con la deriva de las libertades en China. Sus intenciones parecen tan desvestidas de contenido como los cuatro clones de sí mismo en calzoncillos en el cuadro. Se ríen frente a los personajes de enfrente que no sostienen nada pretendiendo parecer que sí. Tanta falsa apariencia pudiera parecer un asesinato por y a la cultura. Hasta ahora, detrás de los cuadros presentados había un tremendo drama, ahora con Yue, solo con una broma parece ser suficiente.

Este artista chino explícitamente se desmarca de cualquier crítica a su gobierno. Todo lo sitúa como una exposición de sus sentimientos, sin postura ideológica, "expresando su confusión sobre lo que él ve». No está de acuerdo en ser tachado de Realista Cínico, término acuñado por el crítico Li Xianting, para referirse a la generación de artistas desilusionados de la era posterior a la matanza de Tiananmen de $1989^{17}$. Quizás simplemente haya que entender este trabajo como la consecuencia de la irrupción de la cultura del capitalismo y del consumismo en la todavía comunista China. Constituiría una subversión de la historia del arte y de su áurea, mediante una estética pop actualizada, que toma y emplea los elementos de los dibujos animados y de la ilustración gráfica. Es una obra expresionista/pop que cruza ampliamente los límites de la caricatura, personajes clónicos, grotescos en un color uniforme de pasta de dientes blanqueadora. Esta obra es también una muestra del antihéroe contemporáneo, en una sociedad que aparentemente promociona la individualidad. Los consumidores somos uniformes en una vacuidad existencial aunque nos creamos únicos, 'diferentes' a los demás. El pelotón no porta armas, eso elimina el suceso, todo se convierte en una farsa, una mera imitación de una escena sin sus consecuencias. Ahora los verdugos y las víctimas son lo mismo, la misma persona, el mismo clon de la imagen del artista repetido como una marca cotizada. Esto es una nueva realidad, nos reímos de todo mientras nos sumergimos en un Mundo Feliz. Este cuadro, al poco tiempo de terminarlo, se vendió en Hong Kong a un marchante por 5000 \$. Estuvo diez años almacenado en Londres antes de ser revendido en 2007. Entonces se hizo famosa por ser la pintura china contemporánea más cara, 5.9 millones $\$^{18}$. Los herederos del comunismo maoísta han aprendido bien a convivir con las reglas especulativas capitalistas.

${ }^{16}$ Andrea Pira, [Chineando] Yue Minjun: La ironía es una tristeza que quiere llorar y sonrie. China files. 17 de dicembre de 2012 https://www.china-files.com/chineando-yue-minjun-la-ironiaes-una-tristeza-que-quiere-llorar-y-sonrie/ (consultada 29-8-20).

${ }^{17}$ Elena Cué, Entrevista a Yue Minjun. Alejandra de Argos. 7 de noviembre de 2014 https:// www.alejandradeargos.com/index.php/es/completas/9-invitados-con-arte/342-entrevista-a-yue-minjun (consultada 29-8-20).

${ }_{18}$ Terry Wise, Why is that man smiling http://www.chinadebate.com/2011/07/execution-byyue-minjun-bought-for-5000-sold-for-5-9-million-why-is-that-man-smiling/ (consultado 10-7-2014). 

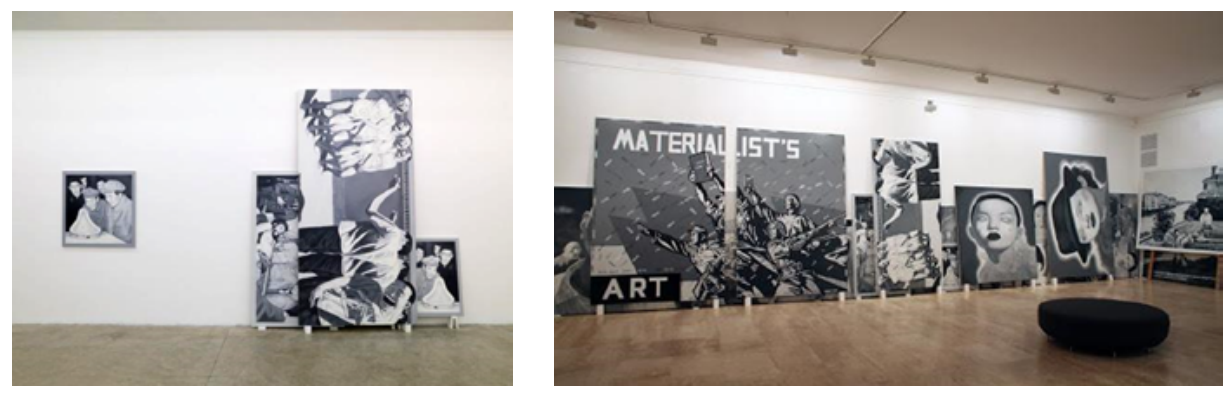

Figs. 25 y 26. Gabriele Di Matteo. China-Made in Italy, 2009.

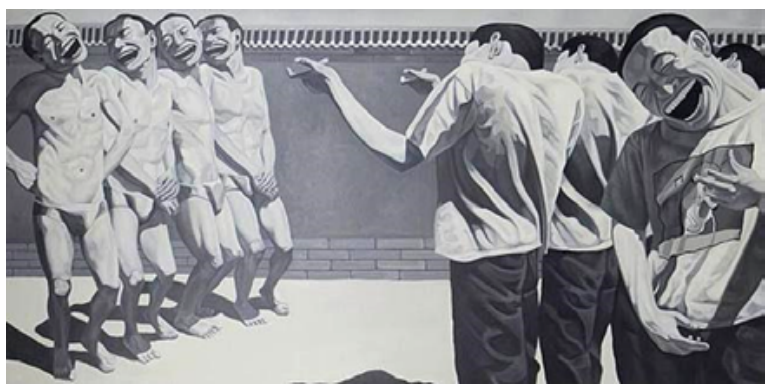

Fig. 27. Gabriele Di Matteo. China-Made in Italy, 2009.

Di Matteo copia en blanco y negro y con el mismo tamaño las obras de Yue Minjun. Es una apropiación mediante la reproducción, una alegoría literal de la copia. La obra plantea semánticamente la relación entre lo real y su reproducción planteando qué es el valor, los derechos de propiedad y copia y el valor de cambio regido por el mercado en la sociedad capitalista. Es el estereotipo de la reproducción sin fin, casi del simulacro, la copia sin un original de Baudrillard, que llegará a su propia extenuación, al "crimen perfecto» que apunta la artista Gloria Fried$\operatorname{mann}^{19}$ : «un proceso de copia que acabará matando al original para convertirse en otro 'original'».

19 Gloria Friedmann, Gabriele Di Matteo. Keitelman Gallery, Bruxelles. 16/10/2009 (Undo.net) http://www.undo.net/it/mostra/93694 (consultado 10-7-2014). Y Flash Art. Di Matteo's copies http://www.flashartonline.com/inclusioni/newsletter_det.php?pagina=newsletter_ det\&id=143\&det=ok (consultado 10-7-2014). 
En su serie China-Made in Italy (figs. 25-27), un proyecto para Unlimited Art Basel 2009, Di Matteo copia además a otros artistas chinos: Zhang Xiaogang, Fen Zhengjie y Wang Guangyi ${ }^{20}$ (fig. 26), hasta cien obras en pastiches en blanco y negro, de una falsedad unívoca. Se muestran amontonados, como en un almacén, cuando es en realidad una galería, desde la fotografía del cadáver del Che Guevara al urinario de Duchamp admirado en la imagen por los jerarcas chinos (véase en doble versión invertida) (fig. 25). Di Matteo se convierte en un artista cotizado en una sociedad en donde lo verdadero y lo falso se confunde, como en el arte, en donde el valor se mezcla con el fetichismo, la comercialización y la marca. Con el título general se podría interpretar como una venganza a los millones de copias chinas de productos originales italianos. El arte representado como una mercancía barata en una mala imitación, al final parece que lo que tiene realmente valor es el logotipo y no el producto ${ }^{21}$.

\section{LAS PINTURAS (QUE YA NO LO SON) VACIADAS}

Hasta ahora se ha asistido a una evolución 'mimética', por la similitud de la imagen, del Tres de mayo. Casi todos los ejemplos han incidido en el esquema compositivo de dos hileras, la de los verdugos (que disparan) y sus víctimas (los fusilados). El Guernica se excluye de este esquema para tomar ciertos elementos (luz y brazos alzados) aunque mantiene la relación de verdugos (como alusión, ya que no aparecen en la imagen) y sus víctimas (bombardeadas). De la imagen como copia (eikon) se pasa a la imagen como simulacro (phantasma $)^{22}$. Mediante una transformación, la eliminación de las figuras, aparece 'un espacio oculto' que antes 'estaba' pero no era percibido debido al protagonismo de la narración de las figuras. Ballester (figs. 28-29) elimina de la vista los personajes que habían servido como modelo original pero que permanecen en la memoria y se imponen como referencia confiriendo de sentido ese espacio vacío (fig. 28) y ese otro (fig. 29) de fragmentos, que como conjunto constituye una ruina. Parece y hace referencia a unas pinturas al óleo, cuando es una fotografía manipulada. Cobra importancia la contemplación de la obra, porque entonces se descubre la impostura de lo que parece una pintura cuando se percibe reproducida (como ocurre ahora en este artículo). Ballester ${ }^{23}$ quiere manipular un espacio clásico por otro desde el presente. Quizás eso justifique por qué no emplea la pintura (él es un excelente pintor) en vez de la fotografía.

${ }^{20}$ Unlimited Art Basel, The China-Made in Italy project, by Gabriele di Matteo. http://gabrieledimatteo.info/china $\% 20$ made $\% 20 \mathrm{in} \% 20$ italy/index.html (consultado 10-7-2014).

${ }^{21}$ Naomi Klein, No logo: El poder de las marcas (Madrid: Booket, 2011) (1. a edición 2000).

${ }^{22}$ Gilles Deleuze, Logique du sens. (Paris: Minuit, 1969): 292-307. En español, Lógica del sentido https://www.uv.mx/tipmal/files/2016/11/Deleuze-Logica-del-Sentido.pdf (consultado 28-8-20).

${ }^{23}$ Canal 1. Entrevista a José Manuel Ballester 19 de abril de 2011 https://videos.cervantes. es/entrevista-a-jose-manuel-ballester/ (consultado 10-8-20) 


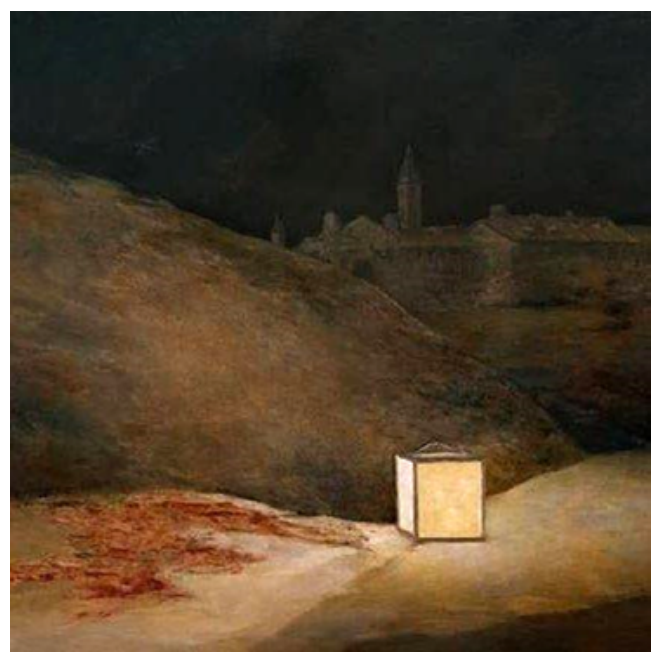

Fig. 28. José Manuel Ballester. Tres de mayo, 2008. Serie espacios ocultos III, pintura española, 2008.

Ese cambio de medio refuerza la idea de la mutación de la imagen que pasa a ser un fantasma de sí misma, de la original.

$\mathrm{Su}$ Tres de mayo vaciado presenta exactamente el mismo espacio físico que el que empleó Goya, $268 \times 347 \mathrm{~cm}$. Se reconoce y explica lo suficiente con dejar los restos del suceso, la sangre, la basura del crimen. La luz permanece encendida, manteniendo la denuncia. La realidad se sustituye por la apariencia de su realidad ${ }^{24}$. Al fondo, la silueta de la oscura ciudad semioculta por el terraplén aporta el murmullo de los habitantes, los autores del crimen y sus víctimas. En esta obra reside la mirada que con su memoria reconstruye lo que allí ocurrió y que acaso sigue y seguirá ocurriendo ${ }^{25}$.

La profusión de restos del Guernica (fig. 29) hace que el vacío sea menos evidente. Permanece la luz, esos rayos de la solitaria bombilla, de las llamas de la derecha, que en su aguda resolución ajena a las ondulantes y etéreas del fuego y la luz se reconocen más como dientes y pinchos agudos. También aquí la memoria hace habitar a los fantasmas de los personajes que Ballester ha suprimido. En

${ }^{24}$ Stoichita se refiere con esto al concepto de simulacro de Baudrillard. Victor I. Stoichita, Simulacros. El efecto Pigmalión: de Ovidio a Hitchcock (Madrid: Ediciones Siruela, 2006): 13.

${ }^{25}$ Ballester afirma: «El arte no cambia la realidad, pero si la forma de entenderla. Después de Goya y del Guernica de Picasso no debería haber más guerras. Sin embargo, existen hoy muchos lugares donde hay conflictos bélicos, enfrentamientos y violencia. Lo que queda de ellos en una sangre no identificada». Francine Birbragher-Rozencwaig. Espacios Ocultos, Entrevista a José Manuel Ballester en http://letraurbana.com/articulos/espacios-ocultos-entrevista-a-jose-manuel-ballester/ (consultado 28-8-20). 


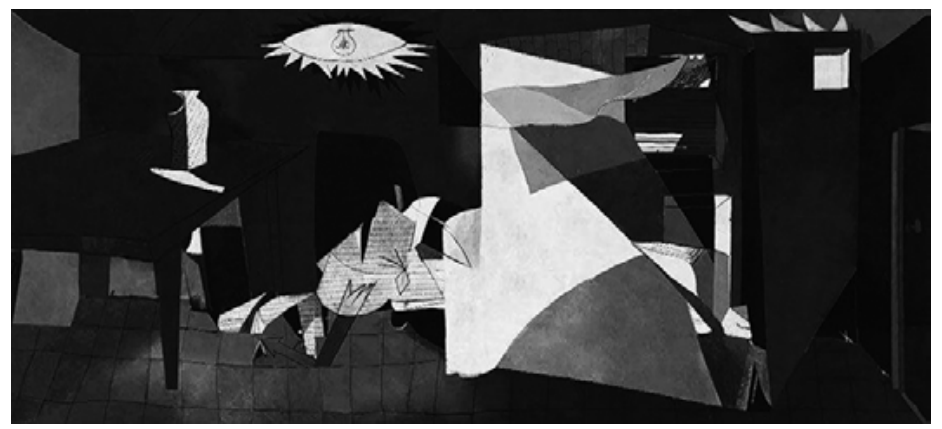

Fig. 29. J.M. Ballester. Guernica. Serie espacios ocultos II, pintura española, 2008.

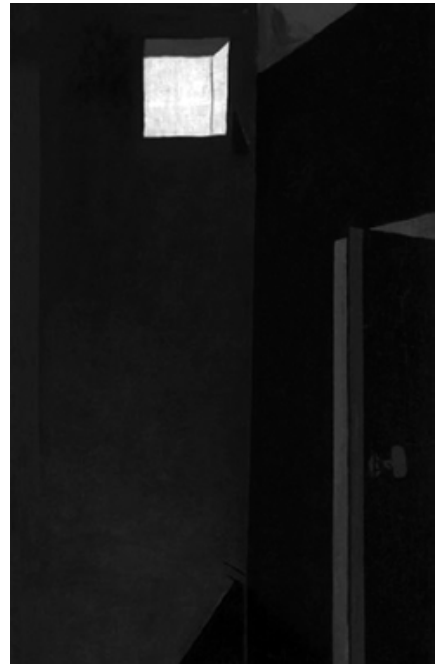

A. Fig. 30.

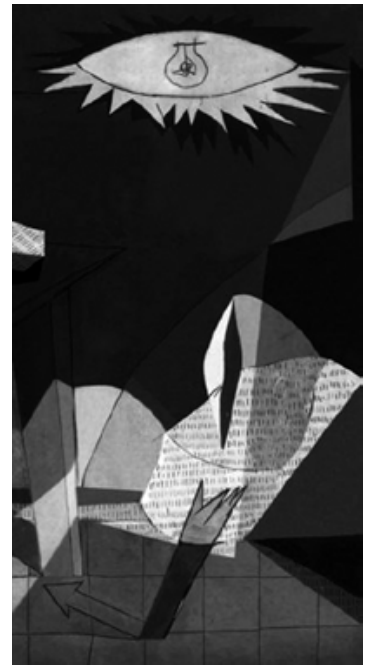

B. Fig. 31.

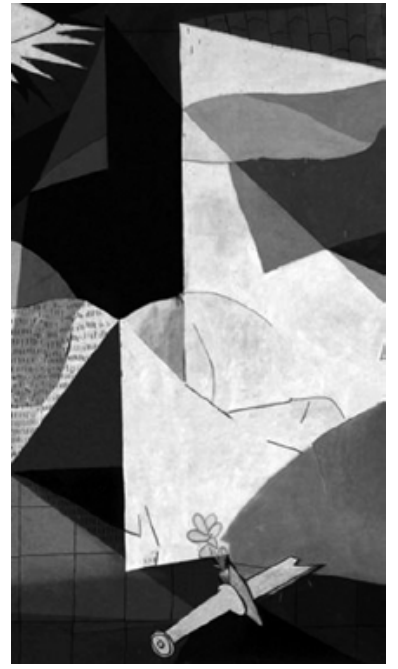

C. Fig. 32.

J.M. Ballester: A) Vacios del Guernica, 2017. B) Luz en el Guernica, 2017.

C) Luz flor del Guernica, 2017.

una versión posterior hace explícitos los fragmentos de la obra completa. Ahora (fig. 30) se singulariza la ventana del edificio incendiado y se comprende mejor La visita del Equipo Crónica (fig. 13), porque hay un espacio iluminado detrás de la tragedia del oscuro escenario del primer término. De entre los restos rotos y heridos de las figs. 31 y 32, una flor que titula la segunda pieza pone de manifiesto el rayo de esperanza que pintó el malagueño. Estos fragmentos vaciados deconstruyen el recuerdo que guardamos del Guernica y por ende de toda la saga de obras que se han presentado. 


\section{CONCLUSIONES}

El Tres de mayo de Goya inicia una saga temática que evoluciona en sus intenciones bajo conceptos mutantes de otros autores. Manet incide en la pintura por la pintura. Gisbert en el documento bajo un impecable neoclasicismo. Picasso recoge algunos elementos para construir algo original con su extraordinario Guernica, manteniendo el binomio de víctimas y verdugos (evocados) para coincidir con Goya en el discurso del drama descarnado y embrutecedor de la guerra. Con Masacre en Corea, imita formalmente a Goya, sin alcanzar las cotas de excelencia del Guernica. Se sigue la saga temática con ejemplos de arte adocenado panfletario, banal y trivial, contrapuesto con la fotografía documental del asunto y sus dos originales variantes de la tragedia como juego (los niños) y como rito (fusilar a un monumento). La sociedad de consumo irrumpe en el asunto con la inteligencia de mensajes estratificados en la brillantez formal del Equipo Crónica. De Minjun con la copia desprovista de la antigua simbología en donde todo es 'una risa'. Di Matteo llega a paroxismo de la copia por la copia del copiador chino. Es la apoteosis de la mímesis, después de la evocación y de la referencia, se llega a la hiperrealidad de la copia. Finalmente Ballester vacía las obras de la referencia de sus figuras para resaltar el espacio oculto, mientras la mirada reconstruye las imágenes ausentes, los fantasmas hijos de la memoria. 


\section{BIBLIOGRAFÍA}

Argam, Gulio Carlo. El arte moderno 1. Valencia: Fernando Torres, 1975.

Arnheim, Rudolf. El Guernica de Picasso. Génesis de una Pintura. Barcelona: Gustavo Gili ed., 1976.

Birbragher-Zozencwaig, Francine. Espacios Ocultos, Entrevista a José Manuel Ballester en http:// letraurbana.com/articulos/espacios-ocultos-entrevista-a-jose-manuel-ballester/ (consultado 28-8-20).

Cabanne, Pierre. El siglo de Picasso III (1937-55). La Guerra. Madrid: Ministerio de Cultura, 1982.

Canal 1. Entrevista a José Manuel Ballester 19 de abril de 2011 https://videos.cervantes.es/entrevista-a-jose-manuel-ballester/ (consultado 29-8-20).

Cú́, Elena. Entrevista a Yue Minjun. Alejandra de Argos. 7 de noviembre de 2014 https://www.alejandradeargos.com/index.php/es/completas/9-invitados-con-arte/342-entrevista-a-yueminjun (consultado 29-8-20).

De Blas, Mariano. Los cuadros de fusilamientos en el siglo xix. Una discusión de intenciones. Bellas Artes: revista de artes plásticas, estética, diseño e imagen n. ${ }^{\circ} 11$. La Laguna: Universidad de La Laguna, 2013.

Friedmann, Gloria. Gabriele Di Matteo. Keitelman Gallery, Bruxelles. 16/10/2009 (Undo.net) http:// www.undo.net/it/mostra/93694 (consultado 10-7-2014).

Flash Art. Di Matteo's copies http://www.flashartonline.com/inclusioni/newsletter_det.php?pagina= newsletter_det\&id=143\&det=ok (consultado 10-7-2014).

Deleuze, Gilles. Logique du sens. Paris: Minuit, 1969: 292-307. En español, Lógica del sentido https:// www.uv.mx/tipmal/files/2016/11/Deleuze-Logica-del-Sentido.pdf (consultado 28-8-20).

Klein, Naomi. No logo: El poder de las marcas. Madrid: Booket, 2011 (1. ${ }^{2}$ edición 2000).

Langlands, Rebecca. Sexual Morality in Ancient Rome. Cambridge: Cambridge University Press, 2006.

National Gallery, The. The execution of Maximilian. https://www.nationalgallery.org.uk/paintings/edouard-manet-the-execution-of-maximilian (consultado 28-8-20).

Penrose, Roland. Picasso. His life and work. New York: Harper\&Row, 1973 (1. a edición 1958).

PIRA, Andrea, [Chineando] Yue Minjun: La ironía es una tristeza que quiere llorar y sonrie. China files. 17 de dicembre de 2012 https://www.china-files.com/chineando-yue-minjun-la-ironia-esuna-tristeza-que-quiere-llorar-y-sonrie/ (consultado 29-8-20).

Stoichita, Victor I. Simulacros. El efecto Pigmalión: de Ovidio a Hitchcock. Madrid: Ediciones Siruela, 2006.

Unlimited Art Basel. The China-Made in Italy project, by Gabriele di Matteo http://gabrieledimatteo.info/china\%20made\%20in\%20italy/index.html (consultado 10-7-2014).

Utrey, Gertje. «From Guernica to The Charnel House: The Political Radicalization of the Artist», en Steven A. Nash and Robert Rosenblum, eds., Picasso and the War Years 1937-1945. New York: Thames and Hudson Inc., 1998.

Utwey, Gertje. Picasso: the Communist Years (London \& New Haven, Yale University Press, 2000).

Van Hensbergen. Gijs. Guernica. The biography of a twentieth-Century Icon. New York: Bloomsbury, 2006. 
WIKIPEDIA. Execution (painting) http://en.wikipedia.org/wiki/Execution_(painting) (consultado 29-8-20).

Wikipedia. Category: Execution of Emperor Maximilian I of Mexico by Manet https://commons. wikimedia.org/wiki/Category:Execution_of_Emperor_Maximilian_I_of_Mexico_by_ Manet (consultado 28-8-20).

WISE, Terry. Why is that man smiling http://www.chinadebate.com/2011/07/execution-by-yue-minjunbought-for-5000-sold-for-5-9-million-why-is-that-man-smiling/ (consultado 10-7-2014).

Xianting, Li. «The Cynical Realist Works of Yue Min Jun and Yang Shao Bin» in Faces Behind the Bamboo Curtain, Hong Kong: Schoeni Art Gallery, 1994.

XIAnting, Li. Yue Minjun Exhibited at The Saatchi Gallery, 2005. http://www.saatchi-gallery.co.uk/ artists/yue_minjun.htm (consultado 29-8-20)

Yuan, Elizabeth. Painting's owner 'un-Executed', 2007. http://edition.cnn.com/2007/WORLD/ asiapcf/10/12/china.artist/index.html (consultado 18-7-17). 